\title{
Australia-New Zealand GARP Symposium 17-19 December 1979, Melbourne, Australia
}

\author{
R. Seaman ${ }^{1}$ \\ on behalf of the local organizing committee
}

\section{Introduction}

This symposium was cosponsored by the Australian Academy of Science and the Bureau of Meteorology (BOM), with the cooperation of the GARP Joint Organizing Committee and the Australian Branch of the Royal Meteorological Society. It was designed to provide a forum for both operational and research meteorologists to discuss both early results and future plans for the use of First GARP Global Experiment (FGGE) data and the impact of FGGE data upon forecasting in the Southern Hemisphere. The meeting attracted 115 participants from seven countries. A limited number of preprint volumes are available. ${ }^{2}$

The opening address was delivered by C. H. B. Priestley (Monash University). As one associated with GARP from its outset, Priestley spoke on the past and future of the FGGE concept. In so doing, he pointed out the danger that the first GARP objective ${ }^{3}$ might receive less than adequate scientific attention in view of the recently instituted World Climate Research Program, and he stressed the obligation of the scientific community to make maximum use of the unique FGGE data sets in pursuit of the former objective.

The following sessions focused upon the themes of 1) observing systems for FGGE, 2) FGGE impact on analysis, 3) FGGE impact on prognosis and forecasting, and 4) diagnostic studies using FGGE data. Most of

\footnotetext{
${ }^{1}$ Australian Numerical Meteorology Research Centre, Melbourne, Australia.

${ }^{2}$ Requests should be addressed to: Mr. J. L. Ginnane, Australian Numerical Meteorology Research Centre, Box 5089AA, Melbourne, Victoria, 3001, Australia.

${ }^{3}$ An understanding of the transient behavior of the atmosphere as manifested in the large-scale fluctuations that control changes in the weather.
}

0003-0007/80/070724-04\$05.00

(C) 1980 American Meteorological Society the papers addressed either the operational impact on analysis and forecasting of the enhanced data base available in real time during 1979 or preliminary research results using II-a and III-a data sets. A few papers addressed future plans and new techniques for utilization of FGGE data.

\section{General impressions}

The most unequivocal message from the symposium was that significant impact upon Southern Hemisphere forecast operations had resulted from the extra data available in real time during FGGE. In particular, the effect of the drifting buoy program had been quite oustanding. These conclusions were substantiated both by performance statistics in 1979 versus previous years and by many case studies of synoptic events presented by both Australian and New Zealand meteorologists.

At such an early date, one could not expect the emergence of definitive research results based upon FGGE data. It was nevertheless clear from several papers that the enhanced data base was already being well utilized in pursuit of a better understanding of the large-scale fluctuations that control the day-to-day weather. It was also obvious that the implications of FGGE for the design of future Southern Hemisphere observing and analysis-forecast systems were considerable. Early results of data assimilation experiments indicated that the enhanced surface pressure network provided by drifting buoys was a crucial element in enabling an ongoing realistic numerical analysis-forecast cycle with minimal manual intervention-something that had not previously been feasible in the Southern Hemisphere.

Less conclusive, but perhaps equally important, were the implications of the enhanced FGGE data base for our knowledge of the Southern Hemisphere climate and general circulation. Three speakers produced evidence that computations based upon 1979 analyses yielded very different results from previous 
years for some climatic parameters. Further research is needed to elucidate which of these apparent differences were due to the poor observational data base prior to 1979 and to what extent 1979 was really an anomalous year.

Representatives of both the FGGE III-b data centers participated in the symposium. L. Bengtsson and K. Miyakoda outlined the respective data assimilation strategies in use at the European Centre for Medium Range Weather Forecasts (ECMWF) and the Geophysical Fluid Dynamics Laboratory (GFDL), and reported on progress and future plans. The inevitable comparisons of the final III-b data sets produced by these two prestigious institutions will surely stimulate fruitful discussion in the years to come. The general circulation model of the U.S.S.R. Hydrometeorological Centre, Moscow, as used for 10 day experimental forecasts, was described by I. V. Trosnikov.

The following sections summarize the presentations relevant to the several themes of the symposium.

\section{Observing systems for FGGE}

Two papers dealt specifically with the performance of the drifting buoy system, and one paper addressed the Southern Hemisphere assessment of the TIROS-N data. Several papers in later sessions referred incidentally to the performance of these and other observing systems in the course of assessing their impacts on analysis and forecasting.

R. S. De La Lande (BOM) reviewed the FGGE buoy systems and indicated potential areas of improvement in future systems. Objectives of accuracy and deployment configuration during FGGE had generally been met. The maximum number of buoys with good pressures available at one time was 206 in early June, and at the end of 1979 , more than 100 were still operating.

R. J. McKenzie et al. (BOM) focused upon the performance of the Australian drifting buoys. A total of 47 Australian buoys were deployed, of which 20 were still operating. Buoy-ship comparisons indicated that accuracy was satisfactory. For an average lifetime, which included eight reports per day, the cost of the buoy system was equivalent to about eight Australian dollars per report.

An assessment of TIROS- $\mathrm{N}$ remote soundings in the Southern Hemisphere from January to August 1979 was given by A. D. F. Wright (BOM), who had been on assignment at the U.S. National Meteorological Center (NMC) during this period. He enumerated some characteristic shortcomings of the data as received at NMC. These were summarized as inaccurate retrievals over land, incompatibility of microwave retrievals with clear and partly cloudy retrievals, biases in some latitude zones, and failure to depict extremes. However, despite these problems, the data were of significant value in defining circulation patterns of the Southern Hemisphere, as was clearly indicated during a short period when no remote soundings were available.

\section{FGGE impact on analysis}

Several papers addressed the impact of FGGE data upon both analysis and prognosis. In this section, only those papers will be mentioned in which the emphasis was on analysis.

M. J. Coughlan (BOM) and B. F. Taylor (New Zealand Meteorological Service (NZMS)) assessed the benefit of sea surface temperatures from drifting buoys to analyses of the Southern Hemisphere and the New Zealand region, respectively. The two studies were in agreement that this component of the drifting buoy program provided data that were generally consistent with ship reports and had been a valuable addition to the sea surface temperature data base.

A perspective on the impact of additional FGGE data upon operational tropical analyses of the Darwin Regional Meteorological Center was provided by $M$. Williams (BOM). The Japanese Geostationary Meteorological Satellite (GMS) had provided the most important source of extra data through visual and infrared imagery and cloud motion vectors. Despite problems in level assignment of the latter, cirrus-level winds in particular had proved very useful. Additional benefit had resulted from a substantial increase in the number of aircraft reports and an upgraded synoptic network.

In a discussion of the impact of drifting buoy pressures on analysis, L. B. Guymer and J. F. Le Marshall (BOM) presented both synoptic case studies and statistics on positions and intensities of pressure systems, from which they concluded that "the true intensity of southern ocean depressions and the violent pressure fluctuations of middle latitude systems were seen as a whole over many areas for the first time." The possible climatic implications of this paper will be mentioned in Section 6 .

Two papers described preliminary results of data assimilation experiments utilizing numerical analysisforecast cycles with minimal manual intervention. Such systems have not been operationally feasible for the Southern Hemisphere in the past because of observational data inadequacies that have necessitated extensive manual input of interpretations of satellite imagery. W. Bourke et al. (Australian Numerical Meteorology Research Centre (ANMRC)) and G. A. Mills and L. W. Logan (ANMRC) presented, respectively, results of experiments for hemispheric and nested regional domains that suggested that the FGGE II-a data base was capable of supporting an automatic data assimilation system, which produced prognoses of a quality at least the equal of existing manually 
interactive systems. The translation of such results into operational reality presupposes the continuation of a data base close to FGGE II-a standards and the availability of computing resources such as are now available to most advanced national weather services. An important component of the assimilation system of Bourke et al. was the normal mode initialization method, the basis of which was presented in a subsequent paper by K. Puri (ANMRC) and R. Daley (National Center of Atmospheric Research, U.S.A.).

\section{FGGE impact on prognosis and forecasting}

Impact assessments in this category were of three types: case studies of synoptic situations where the additional FGGE data had probably resulted in a different forecast of local weather; parallel analysisprognosis cycles over a number of days in which one of the cycles utilized additional FGGE data; and comparisons of overall prognosis performance in 1979 versus previous years. All three methodologies clearly indicated a positive impact of the additional data.

The case study approach was adopted by $R$. A. Hicks, R. J. Keith, and H. Stern (BOM-Victorian region); S. F. Pendlebury (BOM-Tasmanian region); and S. J. West (BOM-Western Australian region). The consensus of these speakers was that the drifting buoy pressure network had resulted in improved weather forecasts on many occasions. The last named speaker presented a graphic case in which the additional information available from buoy pressures and TIROS-N soundings had enabled the prediction of a cold outbreak in the southwest of Australia.

The parallel cycle method of data impact testing was used by R. N. Fitt, F. Whitby, and J. Brown (BOM) and N. D. Gordon (NZMS). The former paper assessed the effect of withholding buoy pressures and TIROS-N soundings from the Australian region numerical analysis-prognosis system, used by the National Meteorological Analysis Center (NMAC). Over 10 winter situations, these data had a combined positive impact of one to three $S 1$ skill score points at levels from the surface to $200 \mathrm{mb}$, and positive impacts of about $3 \mathrm{kts}$ and $0.4^{\circ} \mathrm{C}$ in rms errors at $500 \mathrm{mb}$. Subjective synoptic assessments confirmed the direction of the impact. In a similar study using the NZMS operational numerical weather prediction system, Gordon assessed the individual impacts of buoy pressures and NOAA-5 thicknesses during an eight-day period in February 1979. He concluded that buoy pressures had a beneficial impact of the order of two $S 1$ points, being greatest at the surface. The NOAA-5 thicknesses also had a small positive impact, provided that bad data were detected by the analysis scheme.

The gross impact of the additional FGGE data used operationally during 1979 at the NMAC was indicated by comparative monthly skill scores for each month of 1978 and 1979 presented by Guymer and Le Marshall. The sea level skill scores, verifying over the Australian area, of $36 \mathrm{~h}$ hemispheric predictions showed an improvement over 1978 in each month of the FGGE year. Another assessment of gross impact was presented by R. L. Southern (BOM-Western Australian region). For a three-month period from May to July 1979, the $24 \mathrm{~h}$ sea level pressure prognoses prepared manually at the NMAC had lower mean errors than the same period in 1978 over the southwest of Australia and adjacent ocean areas, despite a higher natural variability during 1979 .

L. Bengtsson (ECMWF) presented a case study of atmospheric blocking during January 1979 in which successful numerical predictions were achieved for 8-12 days using all available Level II-a data and a high resolution global prediction model. By systematic degradation of model resolution, physical parameterizations, domain of integration, and initial data base, the relative importance of each of these constraints was assessed.

\section{Diagnostic studies using FGGE data}

The final session included all those papers that did not fall into previous categories, and as a result was less well focused and is more difficult to summarize than other sessions. Two papers canvassed the question of how reliable were Southern Hemisphere pre-FGGE computations of climatological and general circulation parameters based on analyses over data-sparse areas. Guymer and Le Marshall's paper (mentioned earlier) had suggested that the NMAC sea level pressure analyses during 1979 contained more spatial and temporal variance, in comparison with the years 1973-77, than was consistent with previously observed year-to-year variations. They concluded that the buoy data had introduced analysis changes that pointed to a need for a reappraisal of pre-FGGE surface pressure climatology. G. B. Tucker and W. L. Physick (Commonwealth Scientific and Industrial Research Organization (CSIRO)) presented statistics based upon January and July NMAC analyses that also indicated that 1979 differed from previous years in several respects. But they raised the alternative hypothesis that the FGGE period may have been an anomalous one, and that differences from previous years were not due to the improved data coverage. They presented station data to substantiate the view that 1979 was a strongly anomalous year at several oceanic and Antarctic observing stations. But they pointed out that this conclusion could not necessarily be extended to the Southern Ocean as a whole. N. Nicholls (ANMRC) examined Southern Hemisphere analyses for 1979 from the standpoint of atmospheric energetics, comparing his estimates of zonal and eddy kinetic and available potential energies with those of Price (Tellus, 27, 443-452) for 1972-73. He concluded that differences between his and Price's estimates of zonal 
and eddy kinetic energy were consistent with the expectation from an improved observational network, but differences in zonal available potential energy could not be explained in this way. But whatever the cause, the differences between the 1979 and 1972-73 Southern Hemisphere estimates were much less than the interhemispheric differences observed by Price.

Another group of papers was mainly phenomenological. M. Williams (BOM) used data from the Winter Monsoon Experiment (WMONEX) "quick look" set of analyses and three hourly full disc satellite imagery to examine interhemispheric interaction between the Asian winter monsoon and the Indo-Australian summer monsoon. W. K. Downey (ANMRC), T. Tsuchiya (Meteorological Satellite Centre, Japan), and P. F. Noar (BOM) presented a case study during the SOP-II of a familiar Australian phenomenon-the northwest Australian cloud band. T. N. Krishnamurti (Florida State University, U.S.A.) described the evolution of the Indian summer monsoon using a movie time sequence of analyses during MONEX, and outlined ongoing work on boundary layer dynamics, based on MONEX and other data sets. A related paper (presented by title only) by V. A. Golovastov and V. P. Tunegolovets (Far Eastern Hydrometeorological Institute, U.S.S.R.) used data from the Monsoon-73, Monsoon-77, and MONEX experiments to study ocean-atmospheric interactions associated with the Somali current and the southwest monsoon.

The WMONEX data base was used by P. J. Webster (CSIRO) to study diabatic heating processes in the tropical atmosphere. He focused on the role of extended middle- and upper-level clouds. These were the predominant species of much of the tropical atmosphere, were in most cases associated with synopticscale disturbances, and there was substantial evidence that they were active diabatic heat sources. Of relevance to numerical modeling were a review by J. L. McBride (ANMRC) of cloud mass flux models and a proposal by A. F. Bennett (Monash University) for the design of energy conserving vertical difference schemes in sigma coordinates. Finally, J. F. Middleton (Monash
University) presented a Lagrangian analysis of drifting buoy positional data for January-July 1979.

\section{Concluding remarks}

At a time when the observing phase was barely complete, it was inevitable that the perceived impact of the enhanced real-time data base during 1979 on forecast operations should have overshadowed the very early results of more fundamentally oriented research. As a result of this impact, it is clear that FGGE is already having a substantial effect on the planning of future observing systems in the Southern Hemisphere. In particular, now that operational meteorologists have seen for themselves the benefits of the 1979 drifting buoy network, it is certain that every effort will be made to deploy further buoys in the future.

It is nevertheless useful to view the papers presented at the symposium in the light of the stated objectives of FGGE (GARP Publ. Ser. 11, 1973). These may be summarized as: 1) to obtain a better understanding of atmospheric motion for the development of more realistic models for extended-range forecasting, general circulation, and climate; 2 ) to assess the ultimate limit of predictability of weather systems; 3 ) to develop more powerful methods for assimilation of meteorological observations; and 4) to design an optimum composite meteorological observing system for routine numerical weather prediction of larger-scale atmospheric features. The preceding sections have indicated that work is already well underway in pursuit of all these objectives. In addition, the earliest indications, based largely upon Level II-a and III-a data sets, engender confidence that the aims of FGGE have every chance of being fulfilled.

Acknowledgments. The symposium organizing committee consisted of D. J. Gauntlett (Chairperson), W. P. Bourke, J. W. Kidson, P. F. Noar, P. J. Webster, R. S. Seaman, and J. L. Ginnane (Secretary). Symposium sessions were chaired by R. H. Clarke, D. J. Gauntlett, J. W. Kidson, P. F. Noar, H. R. Phillpot, and N. A. Streten. announcements continued from page 723

\section{Satellite Data Users Bulletin}

The Satellite Data Services Division of Environmental Data and Information Services has issued the second edition of the Satellite Data Users Bulletin. Contained in this issue are: up-to-date descriptions of data available from SEASAT, including a series of illustrations depicting all synthetic aperture radar acquisitions; a description of the evolution of the geostationary satellite system and of products available, including sources of data from the Japanese and
European geostationary satellites (HIMWARI-1 and METEOSAT); a similar description of the evolution of the ITOS/NOAA polar-orbiting satellites and of products available; and an update on TIROS-N, NOAA-6, and NIMBUS-7 coastal zone color scanner. Also included are points of contact for information and data pertaining to LANDSAT and other NASA satellites.

Copies of the current and the previous issues may be obtained from: Satellite Data Services Division, NOAA/ EDIS/NCC, Rm. 606, World Weather Building, Washington, D.C. 20233 (tel : 301-763-8111 ; FTS: 763-8111). 